\title{
PERCEPÇÃO DE ESTUDANTES SOBRE MÉTODOS DE AULA INVERTIDA NO ENSINO DE ENFERMAGEM
}

\section{STUDENTS PERCEPTION ABOUT FLIPPED CLASSROOM METHODS ON NURSING TEACHING}

\section{PERCEPCIÓN DE LOS ESTUDIANTES ACERCA DE MÉTODOS DE CLASE INVERTIDA EN LA ENSEÑANZA DE ENFERMERÍA}

\author{
Ricky Falcão Silva Trindade ${ }^{1}$, Jouhanna do Carmo Menegaz ${ }^{2}$, Geyse Aline Rodrigues Dias ${ }^{3}$, Maria Clara Costa Figueiredo ${ }^{3}$
}

\section{RESUMO}

Objetivo: conhecer a percepção de estudantes de graduação sobre o uso de métodos de aula invertida na disciplina de Enfermagem. Método: estudo qualitativo, descritivo, com participação de oito estudantes do curso de graduação em Enfermagem de Universidade Pública da região Norte do Brasil. Realizou-se a coleta de dados, por meio de entrevista, cuja análise seguiu as fases de codificação, aberta e axial, do método das comparações constantes ordenada em versão trial do programa Atlas TI ${ }^{\circledR}$. Resultados: constituíramse de cinco categorias: Preferências; Percepção dos estudantes sobre aula invertida; Processo de aprendizagem facilitado; Dificuldades e desafios; Sugestões e avaliações. Não há consenso entre os participantes sobre preferências, particularmente, se confrontados os métodos de aula invertida versus métodos tradicionais de ensino. Identifica-se que pelos métodos empregados na disciplina os estudantes percebem promoção e desenvolvimento de conhecimentos e habilidades tanto quanto dificuldades e desafios para a sua integração à rotina de estudo. Conclusão: o estudo revelou que os estudantes têm uma compreensão razoável sobre a aula invertida, quando demonstram conhecimentos, habilidades, assim como dificuldades e desafios relativos à experimentação do método. Entretanto considera-se necessário investigar experiências de estudantes de enfermagem em outros ambientes, para uma compreensão mais profunda de como o aprendizado é afetado por esse modelo.

Descritores: Enfermagem; Ensino; Métodos.

\section{ABSTRACT}

Objective: to know the perception of undergraduate students on the use of flipped classroom methods in a nursing course. Method: qualitative and descriptive study with the participation of eight undergraduate nursing students from a public university located in the northern region of Brazil. Data collection was carried out through interviews, following the phases of open and axial coding from the method of constant comparisons using the trial version of Atlas $\mathrm{TI}^{\circledR}$ software. Results: five categories were constituted: Preferences; Students' perception of inverted class; Facilitated learning process; Difficulties and challenges; and Suggestions and estimates. There is no consensus among participants about candidates, particularly if faced with inverted classroom methods versus traditional teaching methods. By analyzing the methods used in the course, students perceive the promotion and development of knowledge and skills, as well as the difficulties and challenges for their study routine. Conclusion: The study revealed that students have a reasonable understanding of flipped classroom when they demonstrated knowledge, skills, as well as difficulties and challenges related to the experimentation of the method. However, it is considered necessary to investigate the experiences of nursing students in other environments for a deeper understanding of how learning is affected by this model.

Key-words: Nursing; Teaching; Methods.

\section{RESUMEN}

Objetivo: conocer la percepción de los estudiantes de pregrado sobre el uso de métodos de aula invertida en la disciplina de Enfermería. Método: estudio cualitativo, descriptivo, con la participación de ocho estudiantes de pregrado de enfermería en la universidad pública de la región norte de Brasil. La recolección de datos se realizó a través de la entrevista de análisis seguida como fases de codificación abierta y axial, el método de comparaciones constantes ordenado en la versión de evaluación experimental del programa Atlas $\mathrm{TI}^{\circledR}$. Resultados: se constituyeron 5 categorías: preferencias; percepción de los estudiantes sobre la clase invertida; proceso de aprendizaje facilitado; dificultades y desafíos; sugerencias y presupuestos. No hay consenso entre los participantes sobre las preferencias, particularmente si se enfrentan a métodos de aula invertidos versus métodos de enseñanza tradicionales. Identifiqué que, a través de los métodos utilizados en la disciplina, los estudiantes perciben la promoción y el desarrollo de conocimientos y habilidades, así como las dificultades y desafíos para su integración con la rutina de estudio. Conclusión: el estudio reveló que los estudiantes tienen una comprensión razonable de la clase invertida, cuando demuestran conocimiento, habilidades, así como dificultades y desafíos relacionados con la experimentación del método. Sin embargo, se considera necesario investigar las experiencias de los estudiantes de enfermería en otros entornos, para una comprensión más profunda de como este modelo afecta al aprendizaje.

Descriptores: Enfermeria; Enseñanza; Métodos.

${ }^{1}$ Enfermeiro, Mestrando em enfermagem pela Universidade Federal do Pará (UFPA). ${ }^{2}$ Doutora Enfermagem pela Universidade Federal de Santa Catarina. Docente do curso de pós-graduação em enfermagem da UFPA. ${ }^{3}$ Mestre em Enfermagem pela UFPA. Docente do curso de graduação de enfermagem da UFPA

Como citar este artigo:

Trindade RFS, Menegaz JC, Dias GAR, et al. Percepção de estudantes sobre métodos de aula invertida no ensino de enfermagem. Revista de Enfermagem do Centro Oeste Mineiro. 2020;10:e3491. [Access__]; Available in:___ DOI: http//doi.org/10.19175/recom.v10i0.3491 


\section{INTRODUÇÃO}

A formação superior no Brasil traz, ao longo de sua trajetória, a necessidade de compreensão das diferentes tendências pedagógicas que influenciam o processo formativo. Uma tendência pode ser compreendida como uma inclinação, propensão, vinculada ao discurso vigente, manifesto explicitamente em documentos, como a legislação educacional, os projetos pedagógicos, ou, tacitamente, pela prática dos professores. $\mathrm{Na}$ Enfermagem, observa-se que diferentes tendências pedagógicas permeiam o ensino, entendendo-se que é possível que algumas contribuam mais ou menos ao desenvolvimento de competências e habilidades do estudante, diante do que estabelecem as Diretrizes Curriculares Nacionais do Curso de Graduação em Enfermagem (DCNs) de $2001^{(1)}$.

Segundo as DCNs de Enfermagem, a formação tem como objetivo dotar o profissional de conhecimentos ao desenvolvimento e ao exercício de competências específicas e gerais, a saber: atenção à saúde, tomada de decisão, liderança, administração e gerenciamento, educação permanente, bem como de competências e habilidades específicas. Para isso, recomenda-se que a formação deve garantir um processo de ensino crítico, reflexivo e criativo ${ }^{(1)}$.

Em cada área do conhecimento de Enfermagem, com a intenção de atingir os objetivos de cada disciplina e aula ministrada, os professores utilizam um conjunto de métodos de ensino, articulados a estratégias pedagógicas, para facilitar o processo de aprendizagem dos estudantes $^{(2)}$. Na área de Administração, em particular, os métodos mais utilizados são de exposição, planejamento estratégico situacional, metodologia da problematização, por meio do Arco de Maguerez, adotando ainda o uso de tecnologias educacionais ${ }^{(3)}$. Observa-se que existem, também, estratégias pouco utilizadas, entre elas, o modelo Flipped Classroom, o qual, neste texto, será adotada a tradução livre, aula invertida.

Aula invertida é um modelo pedagógico caracterizado pela alteração, na ordem tradicional de atividades de aprendizagem, transformada de aula-estudo-avaliação para estudo-avaliação-aula, sendo que o estudo pode ocorrer de forma individual, em pares ou mesmo em times ${ }^{(4)}$. Essa aula vem sendo utilizada, em cursos da área da saúde, inclusive nos cursos de enfermagem ${ }^{(5-7)}$. Tem-se observado o uso do modelo tanto para facilitar o aprendizado teórico quanto ao desenvolvimento de habilidades práticas ${ }^{(8)}$. Essa flexibilidade é explicada, porque o modelo de aula invertida engloba um conjunto de métodos, como: Just-in-Time-Teaching (JITT), Team Based Learning (TBL) e Peer Instruction (PI). Supõe-se que o modelo de aula invertida tem potencial, dependendo dos métodos utilizados a fim de promover o desenvolvimento de competências e habilidades gerais e específicas ao egresso no curso de enfermagem.

Independente da escolha final do professor por um ou outro modelo, é relevante destacar que há sempre a presença de tendências pedagógicas explícitas ou tácitas ${ }^{(9)}$. Atualmente, a tendência consiste em abordagens de ensino centradas no estudante, com estímulo ao uso de tecnologias educacionais e blended learning, combinando, por exemplo, ambientes virtuais de aprendizagem e aulas on-line com momentos presenciais ${ }^{(3)}$.

$A$ adoção de novos modelos implica um investimento de estudo, planejamento e adaptação do professor ao desenho de diferentes estratégias e ao uso de novos métodos, à mesma medida que demanda a adaptação e planejamento do estudante para a realização das tarefas decorrentes. A aplicação do modelo de aula invertida, por exemplo, encontra dificuldades pela existência de currículos muito rígidos e conteudistas e pela necessidade de maior responsabilidade do estudante, em relação ao estudo prévio, para o sucesso da metodologia, pois nem todos têm a disciplina do estudo em casa $^{(10-11)}$.

Em métodos cuja participação do estudante é requerida, em diversos momentos, como nos inspirados pelo modelo de aula invertida, investimentos iniciais, neste processo de adaptação, são relevantes, em particular, porque há estudos que apontam que alguns estudantes podem preferir métodos tradicionais de ensino à aula invertida, apesar de demonstrarem que ela (aula invertida) contribui para o seu processo de aprendizagem $^{(10)}$.

A aula invertida, enquanto modelo pedagógico inovador, tem grande potencial para contribuir à formação de indivíduos críticoreflexivos e autônomos. Nesse sentido, considerando que a escolha metodológica pode interferir no processo de aprendizagem e, em consequência, na formação profissional, levantase a seguinte questão: qual a percepção dos estudantes sobre o uso de métodos de aula invertida em disciplina de Administração em Enfermagem? 
Para tanto, o objetivo do estudo é conhecer a percepção de estudantes sobre o uso de métodos de aula invertida em disciplina de Enfermagem.

\section{MÉTODO}

Trata-se de um estudo descritivo com abordagem qualitativa baseado na perspectiva da Teoria Fundamentada nos Dados (TFD). Desenvolvida na década de 1960, a TFD difere de outras abordagens, por não utilizar procedimentos pré-dedeterminados e, sim, descobrir conceitos, hipóteses e teorias por meio dos dados. A realidade é compreendida, a partir do conhecimento de percepção um certo contexto tem para a pessoa ${ }^{(12)}$. A análise baseou-se na TFD, porém seguiu apenas as fases de codificação aberta e axial.

O estudo foi realizado, no ano de 2018 , com graduandos em Enfermagem de uma Universidade Pública, localizada na região Norte do Brasil, que cursavam a disciplina Administração de Enfermagem, inserida no quinto semestre de um total de nove, pois se trata de disciplina em que as docentes utilizam métodos de aula invertida em todas as unidades de conteúdo.

Elegeu-se essa disciplina, de forma intencional, por trabalhar com métodos que não são tendência pedagógica no curso em questão. Assim, supunha-se que sua implementação poderia gerar certa resistência aos estudantes por ser considerada uma mudança à cultura da disciplina e da faculdade. Considerando esses aspectos é que surgiu este trabalho, apresentado, originalmente como trabalho de conclusão de curso, vinculado ao macroprojeto de pesquisa "Gerenciamento em Enfermagem: Novas Abordagens de Formação e Trabalho Em Universidade Pública e Hospitais De Ensino", aprovado sob parecer CEP no 2.165.945.

A disciplina Administração em Enfermagem compõe- se de quatro unidades teóricas e, na estratégia desenhada, foram eleitos três métodos de aula invertida para o seu desenvolvimento, a saber: Just-in-Time-Teaching, Peer Instruction e Team Based Learning, como pode ser observado no (Quadro 1).

Quadro 1 - Conteúdos e métodos utilizados na disciplina

\begin{tabular}{ccc}
\hline Conteúdo & Método utilizado & $\begin{array}{c}\text { Número de } \\
\text { tarefas }\end{array}$ \\
Unidade I - Sociedade, Instituição e Organização & Just-in-Time-Teaching & 2 \\
$\begin{array}{c}\text { Unidade II - Bases Teórico-Filosóficas da Administração } \\
\text { e Relações com a Prática Gerencial de Enfermagem }\end{array}$ & Peer Instruction & 2 \\
Unidade III - O Trabalho Gerencial de Enfermagem & Just-in-Time-Teaching & 2 \\
Unidade IV - Processo Administrativo ou Gerencial & Team Based Learning & 4 \\
\hline
\end{tabular}

Fonte: Elaborado pelos autores.

Os três métodos guardam os princípios do modelo de aula invertida, porém têm particularidades que os diferenciam. O método Just in Time Teaching (JiTT) foi proposto por um professor da Universidade Purdue de Indianápolis nos Estados Unidos na década de 90. A sua sequência pedagógica consiste em disponibilização de materiais de forma prévia às aulas (ou sessões), resolução de questões enviadas pelo professor de forma eletrônica, análise das respostas dos estudantes e reformulação do plano de aula pelo professor e finaliza com a aula adaptada de acordo com as respostas dos estudantes da etapa anterior (13). Utilizou-se o JiTT nas unidades I e III. Na unidade I, foi requerida uma tarefa e, na III, foram realizadas três tarefas. Observa-se a sequência pedagógica do método JiTT na Figura 1. 
Figura 1 - Etapas do Just-in-Time-Teaching.

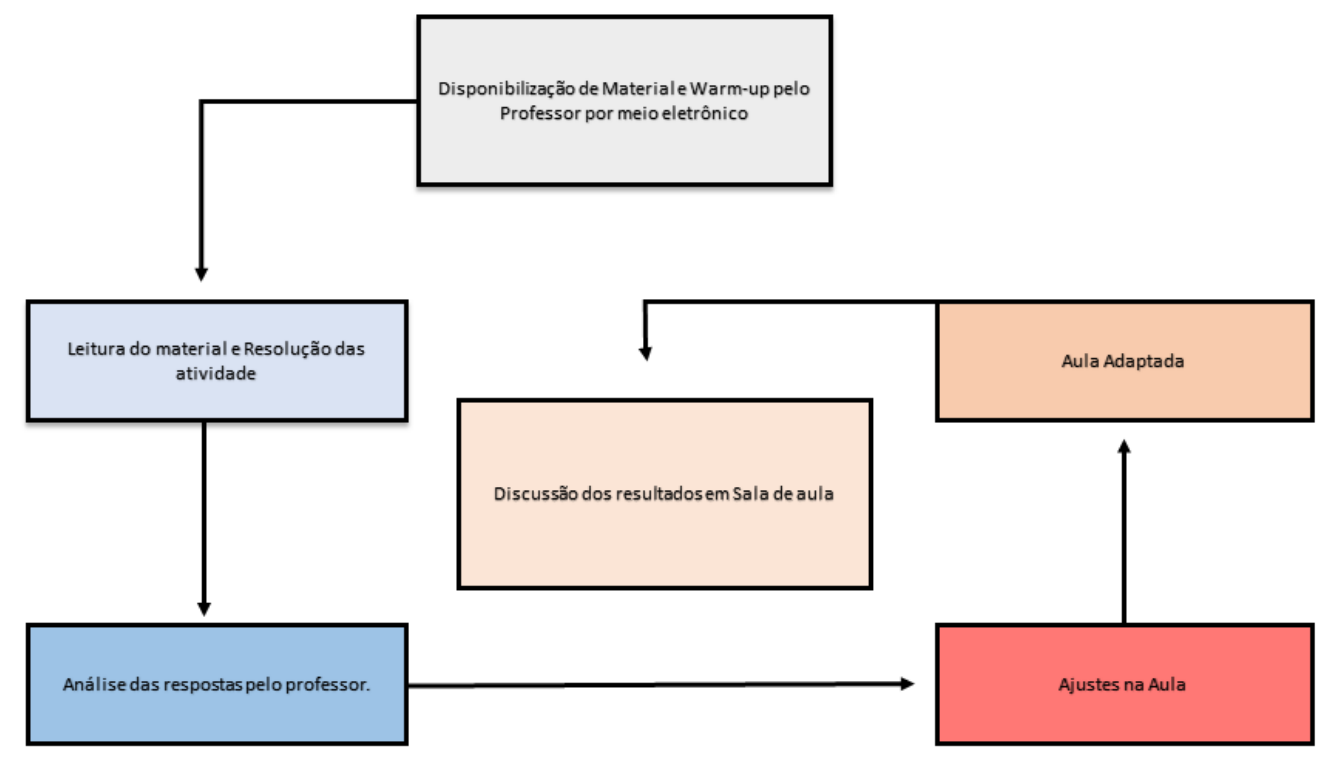

Fonte: Etapas JiTT (4).

Desenvolvido por um professor da Universidade de Harvard, o método (PI) é caracterizado por promover o ensino entre pares, evidenciado pela maior interação entre estudantes para o processo de aprendizagem e discussões sobre os conteúdos estudados ${ }^{(14)}$.

O PI compõe-se de cinco etapas, a saber: 1Exposição inicial do conteúdo pelo professor; 2Aplicação de uma questão conceitual (Concep Test) - questão de múltipla escolha que deve ser respondida de forma individual em tempo prédeterminado pelo professor; 3- Mapeamento das respostas por meio de Clickers ou cartão-resposta (flashcard); determinado pelo professor; 3- Mapeamento das respostas por meio de Clickers ou cartão-resposta (flashcard); 4- Contabilização das respostas e tomada de decisão de acordo com o percentual de estudantes que acertaram a questão da primeira etapa; 5- Finalização da sessão que dependerá do índice de acertos: se menor de $30 \%$, o professor revisará o conceito, entre $30 \%$ e $70 \%$, será aberta a discussão entre pares e, se maior que 70\%, o professor fará suas considerações finais e seguese ao próximo tópico de discussão ${ }^{(13)}$. Utilizou-se o $\mathrm{PI}$, na unidade II (Quadro 1), com a realização de uma tarefa. Observa-se a sequência pedagógica na Figura 2.

Figura 2 - Etapas Peer Instruction.
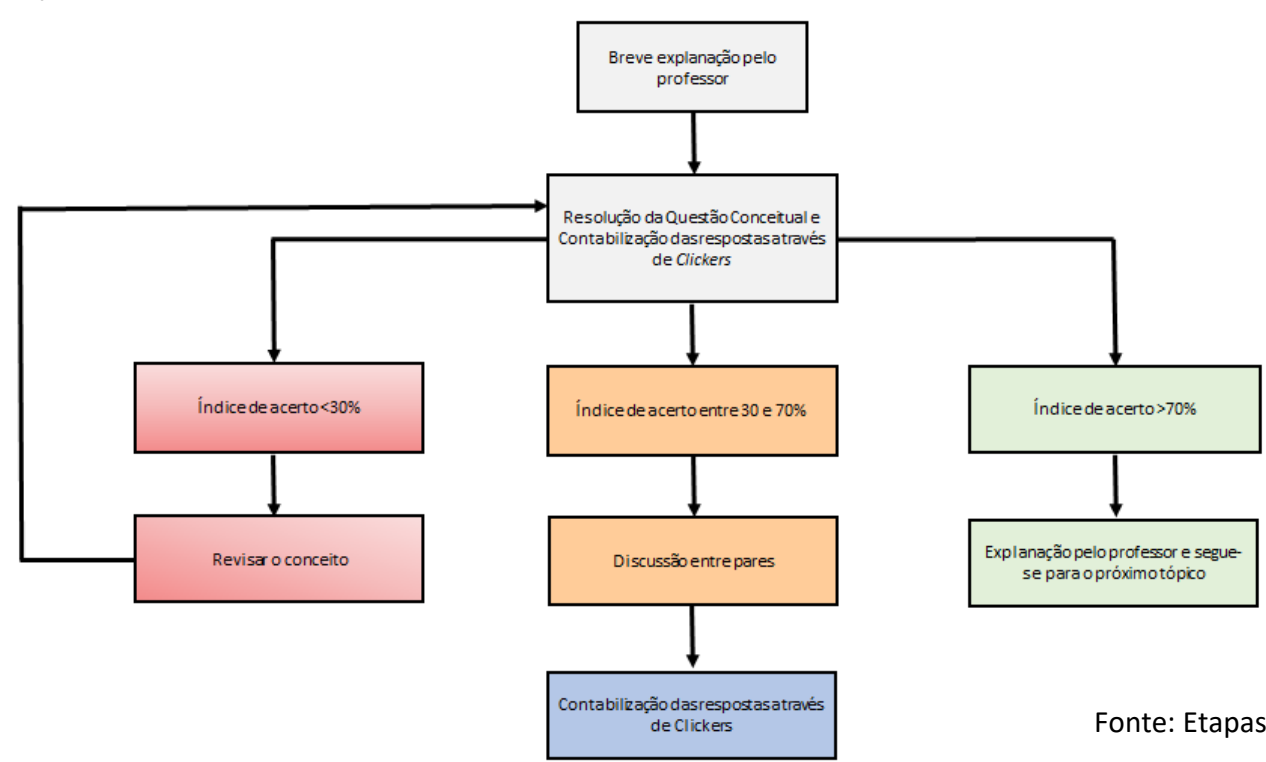

Fonte: Etapas Peer Instruction(4). 
O Team Based Learning foi desenvolvido na década de 70. O TBL propõe a preparação prévia dos estudantes, para as atividades em classe, aprendizado com a interação de grupo e a resolução de problemas do cotidiano profissional $^{(15)}$. É composta por três etapas: 1Preparação individual, cujo professor designa uma atividade pré-classe que pode ser assistir a uma conferência, a um filme, observar um experimento, entre outras; 2- Garantia de Preparo, etapa em que primeiro são respondidas algumas questões de forma individual (Garantia de Preparo Individual) e, em seguida, em Grupo (Garantia de Preparo em Grupo).

Ao fim dessa etapa, deve ser garantido um feedback imediato da resposta correta; 3Aplicação dos conceitos, caracterizado pela aplicação prática dos conceitos discutidos nas etapas anteriores. Os estudantes são convidados a refletir sobre situações relacionadas à sua futura atuação profissional, ou seja, que provavelmente enfrentarão algum dia(16). O PI foi utilizado na unidade IV (Quadro 1) com a realização de quatro tarefas.

Participaram do estudo oito de turma constituída de 29 estudantes, que cursaram a disciplina em questão no segundo semestre de 2017. Foram critérios de inclusão: possuir frequência nas aulas maior ou igual $75 \%$ e a realização de, no mínimo, 70\% das atividades por unidade disciplina.

Optou-se pela frequência mínima, em cada unidade da disciplina de $75 \%$, por ser o mínimo exigido pela instituição e, também, por entender que, a fim de que o participante expressasse melhor sua compreensão sobre o tema, ele precisaria ter participado da maioria das aulas. 0 mesmo justifica para a realização de pelo menos $70 \%$ das tarefas, por cada unidade da disciplina, uma vez que todas as atividades teóricas da disciplina utilizaram métodos de aula invertida.

A coleta de dados foi realizada de janeiro a fevereiro de 2018, após a conclusão da disciplina. Teve como primeira etapa a construção de um quadro para checagem de critérios de inclusão e para a seleção dos participantes. A segunda etapa constituiu-se da realização das entrevistas, com a utilização de roteiro, as quais foram gravadas com o auxílio de gravador de voz e transcritas para o software Microsoft Word. Após a transcrição, foram enviadas por e-mail a cada um dos participantes para que pudessem fazer a validação do conteúdo.
Para a análise dos dados, utilizou-se das fases de codificação aberta e axial do método das comparações constantes ${ }^{(17)}$ ordenada em versão trial do programa Atlas $T I^{\circledR}$. 0 método das comparações constantes aponta que o processo de análise é dinâmico e fluido, todavia, para que se clarifique cada um dos momentos, faz-se necessário o entendimento, o desdobramento em certas atividades e fases ${ }^{(17)}$.

A codificação aberta gerou, a princípio, 25 códigos, porém observou-se que alguns códigos representavam os mesmos fenômenos e, também, que outros tinham um número insignificante de quotations. Após uma revisão detalhada e unificação de códigos que tratavam dos mesmos fenômenos, geraram-se 22 códigos que foram lidos, considerando suas propriedades e dimensões, características comuns e diferenças, eventos e acontecimentos, para então serem incorporados uns aos outros por similaridade.

A criação das categorias (codificação axial) surgiu a partir da íntima relação que as quotations de determinados códigos guardam entre si. Observou-se que era possível agrupar os códigos em categorias, pois tratava-se dos mesmos fenômenos, mesmo que nem sempre integralmente iguais. Assim, durante a codificação axial, os códigos foram articulados em cinco categorias: Preferências, a Percepção dos estudantes sobre aula invertida; Processo de aprendizagem facilitado; Dificuldades e Desafios; Sugestões e avaliações.

Todos os participantes do estudo assinaram o termo de consentimento livre e esclarecido e foram informados sobre seus direitos. Para preservar o anonimato dos participantes do estudo, optou-se por omitir o nome da disciplina, descrevendo um nome fictício. Os participantes são descritos neste estudo com a letra $P$, seguida dos numerais de 1 a 8 (exemplo, E1, E2, E3...). Além dessa explicação, tendo em vista a linguagem utilizada neste texto, cabe um pequeno glossário.

Ainda, de acordo com o conceito de tendência pedagógica, já apresentado no início do artigo, cabe elucidar que se empregou, ao longo de todo o texto, os conceitos de modelo, estratégia e método. O primeiro é a representação do entendimento de como ensinar; o segundo é a forma eleita pelo professor para coordenar este modelo, por meio de vários métodos em seu contexto; e o terceiro é o passo a passo de aplicação do modelo e da estratégia. Há, portanto 
um entendimento de hierarquia, representado da seguinte maneira: tendência (abordagem centrada no estudante) $>$ modelo (aula invertida) $>$ estratégia (combinação de métodos empregados em disciplina de Administração em Enfermagem) > método ( $\mathrm{PI}, \mathrm{JiTT}, \mathrm{TBL}$ ).

\section{RESULTADOS E DISCUSSÃO}

Serão apresentadas e discutidas as cinco categorias articuladas durante a análise. A primeira é a categoria Preferências, pois é, a princípio para a compreensão da percepção do estudante. É necessário entender quais são suas predileções didático-metodológicas e de aprendizado.

Em seguida, Aula invertida - a percepção dos estudantes, pois se trata de como os estudantes compreendem a estratégia pedagógica e também as suas primeiras impressões de como se deu o seu desenvolvimento durante a execução da disciplina. Seguindo, Processo de aprendizagem facilitado, pois já entendidas as preferências dos estudantes e suas compreensões sobre o método, podem-se analisar alguns dos benefícios relacionados à estratégia implementada na disciplina e o desenvolvimento pessoal, de habilidades e valores.

Em seguida, Dificuldades e Desafios, pois são apresentadas as dificuldades e desafios encontrados, durante todo esse processo, atuando como um diagnóstico e, por fim, Sugestões e avaliações, em que algumas dessas dificuldades e desafios são discutidas, avaliadas e até mesmo são sugeridas algumas mudanças para a melhoria do desenvolvimento da disciplina.

\section{Preferências}

Para analisar a utilização de métodos de aula invertida, é necessário considerar que, independente da estratégia e dos métodos eleitos, os estudantes têm meios distintos de perceber, reter, processar e organizar o conhecimento $^{(18)}$. Logo a preferência do estudante é relacionada ao seu estilo de aprendizagem. Ainda que isso reconhecido, nesta categoria, os participantes não serão separados por estilos (visuais, auditivos e cinestésicos, por exemplo) e, sim, listados os relatos de preferências de estudo, buscando compreender relações entre elas e o que se requer do estudante em métodos de aula invertida.

Identificou-se que a leitura prévia é considerada por parte dos estudantes como importante ao aprendizado, "eu aprendo melhor quando eu faço uma leitura prévia do assunto. Então, quando eu venho para a aula que a professora explica, já posso tirar as dúvidas que tive fazendo a leitura e posso tirar outras dúvidas durante o decorrer da aula" (E2).

Esse é um dado importante se for considerado que, na aula invertida, o estudo individual é, em geral, a primeira etapa do processo. Um estudante que tem por hábito ler o conteúdo previamente pode enfrentar menos dificuldades na integração de métodos de aula invertida à sua rotina de estudo. Para estimular o estudo individual, múltiplas estratégias têm sido utilizadas à oferta do conteúdo de maneira virtual, incluindo áudios, vídeos, módulos on-line interativos, o que permite ao estudante flexibilidade, durante $o$ processo de aprendizagem, ao mesmo tempo em que aumenta a autonomia em seu aprendizado, possibilitandoIhe maior diálogo com o corpo docente em sala de aula $^{(19)}$.

Além da preferência por leituras prévias dos conteúdos, alguns estudantes preferem realizar anotações, durante as aulas teóricas, para posterior estudo, escrever e ler as próprias notas sobre determinado conteúdo, relaciona'-las a alguma situação ou contexto real e, também, simplesmente comparecer às aulas.

A variedade de preferências pode ter relação com a predileção a determinados métodos de ensino. Nesse sentido, observou-se que os estudantes que mencionam fazer suas próprias anotações, em vez de somente copiar as colocadas pelo professor no quadro, preferem metodologias centradas no estudante, como é o caso da aula invertida, observado na fala "eu acho que quando a aula, ela foge um pouco do tradicional, ela tende que o aluno preste mais atenção na aula, então as metodologias que são mais inovadoras, elas me chamam mais atenção" (E4).

Por outro lado, alguns estudantes que afirmam que aprendem melhor apenas comparecendo às aulas e tomando notas das explanações do professor demonstram predileção a métodos tradicionais de ensino, por exemplo: "como a minha vida inteira foi estudando pelo método tradicional, então eu meio que criei um sistema onde eu consigo aprender melhor por ele, mas tendo essa, esse contato, não é, com essa nova metodologia, tipo, logo de início eu senti bastante dificuldade, mas depois eu consegui, consegui fluir, vamos dizer assim, mas assim, se eu 
tiver escolha como já é um método que eu já estou acostumada, eu escolho o tradicional( ${ }^{(\mathrm{E})}$.

Compreende-se que o processo de aprendizagem é pessoal, logo um processo diferenciado para cada indivíduo. Nesse contexto, vale a reflexão por parte do professor sobre a importância de conhecer a turma e considerar as preferências dos estudantes, para obter maior eficácia no processo de ensino e aprendizagem, já que a efetividade dos métodos de ensino está relacionada à intensidade de como cada indivíduo aprende de maneira diferente, o que faz com que determinados métodos sejam efetivos para um público e não para outro(18).

Além disso, observaram-se algumas afirmações que sugerem a compreensão dos estudantes de que existem melhores estratégias de ensino e métodos para cada conteúdo e/ou contexto. Dessa forma, a escolha da melhor estratégia de ensino pode variar em cada situação, como observado na fala "existem conteúdos que, assim, o professor deveria realmente dar aquela aula tradicional, a gente está ali, escuta, ele passa, ou uma forma, por exemplo, assim, bem técnica de ensino tipo como o laboratório (E1).

Porém é necessário entender como os estudantes enxergam a aula invertida, para a melhor compreensão sobre suas preferências, pois podem ter uma relação de como o método é observado por eles. Essa visão dos estudantes é discutida na categoria seguinte.

\section{A percepção dos estudantes sobre aula invertida}

Aula invertida é um modelo pedagógico caracterizado pela alteração na ordem tradicional de atividades de aprendizagem, transformada de aula-estudo-avaliação para estudo-avaliação-aula, sendo que o estudo pode ocorrer de forma individual, em pares ou mesmo em times ${ }^{(20)}$. Os alunos aprendem novos conteúdos, em geral, em casa, por meio de textos e vídeos-tutoriais on-line, e o que costumava ser uma lição de casa passa a ser realizado em sala de aula, com orientação personalizada e interação com os estudantes ${ }^{(21)}$.

Em relação às características da aula invertida, identificou-se que os participantes compreendiam a essência desse modelo pedagógico, que é a inversão da sequência tradicional "Bom, eu entendo que é invertido no sentido que antes, tradicionalmente primeiro, a gente assistia à aula e depois a gente ia estudar para a prova ou estudar porque queria estudar o assunto. A aula invertida é o contrário, primeiro eu estudo $\mathrm{o}$ assunto para depois eu assistir à aula" (E3) como também em “(...) É, quando temos acesso ao material antes da aula e a oportunidade de estudar antes de chegar na hora da aula e, dessa forma, poder debater sobre o assunto" (E3).

Observou-se, ainda, que cada método gerou um conjunto de afirmações que se relacionam. Cita-se o Just-in-Time-Teaching, a partir de uma série de afirmações sobre considerar o conhecimento dos estudantes, quando na atuação do professor, para o desenvolvimento do método: "elas também ouviram nossas informações, aquilo que a gente colaborou com a aula, elas destacaram e comentaram nossas opiniões sempre respeitando também a opinião do aluno, mas fazendo o aluno refletir naquilo que ele tinha anteriormente pensado naquele contexto ${ }^{(E 6)}$. Esses dados refletem uma característica desse método, visto que, de acordo com suas etapas metodológicas, o professor precisa ler as respostas dos estudantes e construir uma aula direcionada às suas necessidades. ${ }^{(13)}$.

Além disso, como essa abordagem promove a apropriação de aprendizado por parte dos estudantes, por meio da conclusão do trabalho preparatório e por ser mais interativa, durante o horário real da aula ${ }^{(22)}$, sugere-se, no contexto aqui estudado, que houve o envolvimento dos estudantes, no desenvolvimento dos métodos, bem como a compreensão sobre a importância da sua participação antes da aula e interação com os professores, durante o encontro pedagógico, mesmo que não necessariamente sendo os métodos e as atividades que correspondem à preferência de alguns dos participantes.

\section{Processo de aprendizagem facilitado}

Essa categoria aborda a percepção dos estudantes sobre o processo de aprendizagem de conteúdo pelos métodos, assim como do desenvolvimento pessoal dos estudantes, de habilidades e o aprimoramento de alguns valores.

0 primeiro ponto destacado pelos participantes refere-se ao desenvolvimento ou ao exercício da autonomia em relação ao processo de aprendizagem. $O$ modelo de aula invertida exige do estudante preparo prévio, mas, em momento algum, é obrigado a fazer a leitura de material antes das aulas, ou responder aos questionários pré-casse (no caso do JITT).

A autonomia pode ser observada na fala “(...) então ela veio para nos ajudar para que tornássemos autônomos o nosso aprendizado.Essa proposta torna o ensino e 
aprendizagem mais participativos, colocando o aluno como o principal responsável pelo seu aprendizado (...)" (E1). Vale lembrar que o modelo aula invertida é centrado no estudante ${ }^{(20)}$. Assim, a assunção da responsabilidade da parte que lhes cabe sugere sua aceitação, mesmo enfrentando um processo de mudança, considerando a cultura de uso de métodos de ensino tradicionais.

A tendência pedagógica atual se propõe a promover habilidades colaborativas ou 0 aprendizado em equipe como uma das habilidades de aprendizado do século XXI, mas, para tanto, é necessário que os professores promovam aos estudantes processos de aprendizagem colaborativa ${ }^{(22)}$. Nesse sentido, o TBL foi dentre os métodos utilizados o mais citado pelos estudantes como estimulador e desenvolvedor de habilidades para o trabalho em grupo e de responsabilização por suas tarefas. 0 TBL mostrou-se o método mais comentado pelos participantes e o preferido entre os três desenvolvidos: "Eu entendo que o TBL é muito importante também, porque, às vezes, a linguagem do professor não é tão acessível para a gente, mas quando você está conversando com um amigo, às vezes, você consegue se abrir mais, então você consegue compartilhar aquele conhecimento e construir. No TBL a gente tem uma discussão em grupo e consegue compartilhar isso entre os pares, entre os iguais para poder jogar para o professor" (E1).

O TBL propõe a preparação prévia dos estudantes, para as atividades em classe, aprendizado com a interação de grupo e a resolução de problemas do cotidiano profissional ${ }^{(14)}$. Para tanto, infere-se que o TBL pode estimular o trabalho em grupo pela sua sequência metodológica: resolução de exercícios de forma individual e, em seguida, resolução de exercícios em grupo $^{(15)}$. Na fase de grupo, os estudantes podem discutir entre si e escolher uma resposta, podendo ser diferente daquela escolhida de maneira individual ${ }^{(16)}$.

Essa discussão pode ser mais bem compreendida, a partir da fala “(...) só que a gente tem um momento individual e a gente tem que ter consciência que se a gente não estudar vamos prejudicar todo o grupo. Quando todos estudam, há o sucesso do grupo: cada um tem a sua habilidade, a sua competência em alguma coisa, por isso, é um time (...)" (E1). Atingir esse nível de responsabilidade pelo desenvolvimento do processo de aprendizado favorece o diálogo entre os estudantes, possibilita a escuta e emissão de opinião, bem como a liderança no que refere ao desenvolvimento da capacidade de trabalhar em equipe.

Tais falas dialogam com 0 as DCNs, principalmente, no que se refere às competências e habilidades gerais do egresso no curso de Enfermagem: ouvir e conseguir também transmitir sua opinião (habilidade de comunicação), liderança e a capacidade de conseguir trabalhar em grupo ${ }^{(1)}$.

\section{Dificuldades e Desafios}

Ainda que a percepção dos participantes sobre os métodos de aula invertida tenha sido majoritariamente positiva, alguns estudantes relataram dificuldades e desafios iniciais, fato corroborado por outro estudo ${ }^{(20)}$. Nomearam-se desafios os que foram inicialmente vistos como dificuldades, mas que foram superados pelos participantes, e dificuldades aquelas percebidas como intransponíveis até o momento de conclusão da disciplina. Entre as dificuldades, foram analisadas as diretamente relacionadas aos métodos e dificuldades pessoais.

Nesse sentido, destaca-se o desafio de se trabalhar com métodos de ensino diferentes dos métodos convencionais, ou seja, o desafio de passar por um processo de mudança percebido em "eu me senti desafiada primeiramente porque eu ainda não tinha ouvido falar sobre estas maneiras de se aplicar a aula, então, para mim foi desafiador" (E4) e em "(...) e também porque como a gente já vem de toda uma formação que a gente é basicamente massacrado só com a aula tradicional quebrar de uma hora pra outra sem, sem ter uma passagem mais fluída, eu acho que isso prejudica um pouco" (E7).

Considera-se um evento comum o sentimento de "estranheza" quanto a um processo de mudança, sobretudo, quando se refere à mudança de uma cultura ${ }^{(23)}$. Trata-se da resistência a métodos de ensino desconhecidos, geralmente os aprendizes estão acostumados com métodos tradicionais e carecem de experiências com abordagens centradas no estudante ${ }^{(6)}$. Parte dos professores universitários ainda se utiliza de métodos tradicionais para ensinar. $E$ os estudantes que se acostumaram a ouvir exatamente o que precisavam saber sentem-se desconfortáveis, quando percebem que, na verdade, sua aprendizagem é majoritariamente de sua responsabilidade ${ }^{(19)}$.

A introdução de novos hábitos, na rotina de estudo, foi ao mesmo tempo desafio e dificuldade, 
caso da necessidade de leitura prévia, que se mostrou laboriosa para alguns estudantes “(...) e como eu te falei o hábito da leitura não é comum para gente, não é cultura, então, assim, acho que esse é um dos desafios que os professores enfrentam (...)"(E1). Em vista disso, para se beneficiar plenamente da abordagem de sala de aula invertida, sugere-se que os benefícios adicionais, de combinar o estudo prévio com o ensino presencial, precisam ficar claros aos alunos e serem constantemente estimulados, para que esses momentos não sejam visualizados separadamente, ou como alternativa ao outro, negando o valor de inverter a sala de aula ${ }^{(24)}$.

O trabalho em grupo foi mencionado como dificuldade no processo de aprendizagem, decorrente dos métodos utilizados “(...) como foi dividido em grupos, onde cada um tinha uma característica, foi complicado porque a característica aonde eu estava era liderança, então havia uns embates externos, onde, sendo honesta, havia um querendo ser o líder, só que não havia um líder, havia sim um grupo"(E4).

No contexto do estímulo ao desenvolvimento do trabalho em equipe, geralmente, a designação, para a formação de grupos aleatórios, inicialmente, não é bem vista, os estudantes preferem sentar-se com seus amigos, entretanto observa-se que, ao longo do semestre, eles tornam-se mais interativos, ficando mais à vontade e sentindo maior necessidade de compartilhar seus trabalhos e atividades coletivas $^{(18)}$.

A dificuldade de acesso aos materiais por email, por carência ou ausência de acesso à internet, como demonstrado “(...) em relação aos exercícios pela internet eu senti um pouquinho de dificuldade porque não é sempre que eu estou com acesso à internet" $(\ldots)^{(E 7)}$. Em geral, essas dificuldades estão relacionadas ao modelo, em razão de as características de como os métodos são desenvolvidos. É necessário estudo prévio, os materiais são disponibilizados pela internet, $e$ mail, cloud, drive, entre outros e, no caso do TBL, durante sua etapa de garantia de preparo, possui uma atividade em grupo ${ }^{(15)}$. Porém o método pode ser adaptado às características dos estudantes e do contexto, nesse sentido, a estratégia que as docentes utilizaram para os estudantes com dificuldade de acesso à internet foi disponibilizar o material de forma impressa.

Das dificuldades que não estão diretamente relacionadas ao modelo, merece destaque a de conciliar as atividades de todas as disciplinas do semestre, sugerindo que não houve integração na construção dos planejamentos: "(...) foi difícil conciliar as atividades, sem contar que têm pessoas que não se envolvem com as atividades e você acaba ficando sobrecarregado (...)"(E2).

Essas dificuldades podem estar relacionadas ao desafio que os estudantes encontram em se manterem organizados com suas atividades acadêmicas, fora do ambiente da faculdade e por considerarem, às vezes, excessivo o estudo extraclasse, em geral, por não considerarem a necessidade de carga horária para a sua preparação fora do contexto tradicional de sala de aula ${ }^{(18)}$.

\section{Avaliações e Sugestões}

A implementação de estratégias, baseadas no modelo de aula invertida, ainda, sofre com certa lacuna identificada na descrição dessas práticas. Verifica--se que não há um padrão para a intervenção ${ }^{(6)}$, mesmo valendo-se de métodos bem delineados, como os utilizados no contexto aqui estudado. Logo testar elementos específicos ou componentes do modelo e avaliar as experiências é fundamental para atingir a eficácia esperada na utilização desses métodos.

Para tanto, esta categoria aborda o conjunto de avaliações dos estudantes: sobre as docentes da disciplina, sobre a estratégia, sobre si mesmos e também agrega sugestões para a melhoria da didática e automelhoria.

Os estudantes avaliaram-se, na maioria das vezes, de forma positiva, comentando sobre o seu comportamento e desempenho ao longo da disciplina. Esses dados sugerem uma satisfação pessoal com o seu desenvolvimento, como pode ser observado em "Eu acho que eu (me) daria 7,0 (pontos), talvez eu devesse ter lido mais, mais outras coisas: ter buscado mais assunto, não ter ficado só com o que foi dado, entende? Poderia ter pesquisado mais, me aprofundado mais, já que era algo do meu interesse"(E4) e na fala “(...) eu acho que sempre fui bastante curioso, entende? Sempre mostrei bastante interesse mesmo em pesquisar, conhecer algo e trazer aquilo para a prática, então, eu pego as bases teóricas, assim me proponho a ler os textos, entendeu? (...)"(E6) $\mathrm{e}$ também em "Olha, eu me avaliei muito bem, eu me avalio muito bem, tipo eu tenho em mente que [por] mais que não seja uma disciplina que inspire muita curiosidade e por ser bem burocrática e não ter um fator de levar a gente para o hospital, para assistência direta, inspirou-me um pouquinho de curiosidade $(. . .)^{(E 7)}$. 
Em outra realidade de formação em Enfermagem, os estudantes compreenderam a responsabilidade como parte central da experiência no modelo de aula invertida, em referência a si mesmos, a outros membros do grupo ou ao professor e, quando enquadrada positiva ou negativamente, a responsabilidade, muitas vezes, coincidiu com a disposição de aprendizado do aluno no contexto da experiência ${ }^{(6)}$.

Nessa perspectiva, quanto à implementação da estratégia e dos métodos pelas docentes, as avaliações foram mais críticas, sugerindo que os estudantes têm maior facilidade de avaliar os professores que a si mesmos: "Eu não sei explicar, eu acho que falta um pouquinho mais de eloquência mesmo, desenvolvimento de raciocínio dentro da visão que ela (professora) está querendo mostrar para o aluno e tipo, às vezes, ela meio que se perde na aula, acho que até mesmo pelo conteúdo se tornar um pouco difícil de ser repassado, então, às vezes acaba não, não alcançando o conhecimento dos alunos" ${ }^{\prime(E)}$ e em “A Professora (removido) é bastante comunicativa... A gente vai conversar com ela e ela já fala outros pontos, que não tínhamos pensado, eu acho que ela é bastante crítica, isso ajuda a gente a desenvolver e ver outros pontos de vista e criar situações também envolvendo resolutividade" (E2) também em "(...) a Professora (removido) ela é extremamente metódica, organizada e competente. Acho que as duas se completam e conseguem transmitir justamente o que foi proposto para esse semestre de organização dos serviços de saúde"(E5).

Observa-se que os estudantes percebem as docentes da disciplina de formas distintas. É importante refletir que cada professor utiliza de didática própria, em uma mesma disciplina e que cada estudante percebe os fenômenos ao seu redor de forma diferente. Nesse sentido, não é estranho existirem avaliações divergentes. Todavia, em disciplinas em que haja divisão de atividades e um conjunto de professores, o planejamento deve envolver a capacitação pedagógica e o diálogo constante.

Vale ressaltar que, na utilização de métodos de aula invertida, a responsabilidade do aluno e do professor está intrinsecamente ligada. Enquanto o estudante eleva a responsabilidade por sua própria aprendizagem, nos momentos de estudo individual ou por pares, o professor dedica-se a utilizar o tempo que tem com os estudantes em sala de aula, para auxiliá-los à aplicação de conhecimentos de ordem superior, no lugar de palestras com conhecimentos diretivos, que envolvem a minoria dos estudantes ${ }^{(25)}$.

Nesse contexto, os estudantes também apresentaram sugestões, merecendo destaque as sugestões para a melhoria da estratégia "Acho que, assim, teve alguns conteúdos da disciplina que deveriam ter sido ministrados pra gente que não foram, por exemplo, a gente foi pra prática e não conseguiu desenvolver (...)"(E1) e em "Eu acho que ela trabalhou muito com o conteúdo puro e esqueceu um pouco de trazer isso um pouco para a enfermagem, ou poderia ter sido trabalhado assim: "qual a relação disso com o SUS? (...)"(EG).

As falas sugerem que outros conteúdos sejam incluídos, para o melhor desenvolvimento das aulas práticas e que sejam abordados em um contexto mais relacionado com a enfermagem. Observa-se que alguns estudantes foram mais críticos que outros, apesar de ter sido trabalhada a mesma estratégia com todos, assim, reflete-se que a experiência pedagógica é individual. Nessa perspectiva, outros estudos sugerem que, no futuro, seja desenvolvido um instrumento de pesquisa que avalie o estilo de aprendizagem dos estudantes, para ampliar a capacidade de coleta de dados sobre os valores, preferências e experiências dos estudantes relativos à aula invertida ${ }^{(6)}$.

\section{CONSIDERAÇÕES FINAIS}

O estudo revelou que os estudantes têm uma compreensão razoável sobre a aula invertida, quando demonstram conhecimentos, habilidades, assim como dificuldades e desafios relativos à experimentação do método. Para eles, entre os métodos experimentados, o TBL é o que mais estimula e possibilita o desenvolvimento de habilidades ao trabalho em grupo e de responsabilização por tarefas. Como desafios, percebem estranheza na utilização do novo, em relação aos métodos tradicionais e, em consequência, dificuldade relativa à organização pessoal quanto às atividades propostas pela aula invertida.

A maioria dos estudantes avaliou-se de maneira positiva, durante a utilização dos métodos e divergiram na avaliação das docentes, todavia vale refletir que a experiência pedagógica é individual. Como melhorias, eles sugerem que outros conteúdos relativos à disciplina, que favoreçam as aulas práticas e estejam mais relacionados ao contexto da enfermagem, sejam incorporados às aulas invertidas. 
A utilização dos métodos de aula invertida representa uma inovação, no âmbito do ensino de Enfermagem, logo estimar a percepção de estudantes sobre o uso desse modelo pedagógico reflete um impacto, não somente para o contexto em questão, mas para favorecer e ampliar a implantação e implementação de métodos dessa natureza visando atender as necessidades da formação, assegurando que os estudantes estejam sendo preparados, para a complexa prática de enfermagem, nos diferentes centros de saúde.

Há de se considerar o impacto do estudo para a disciplina, visto que é uma fonte de indicadores sobre o seu desenvolvimento e, por isso, pode ser utilizada como instrumento para mudanças e melhorias. E por ser uma das únicas disciplinas de administração da instituição, o seu desenvolvimento constante pode ter impacto ainda mais na formação dos próximos estudantes. $O$ estudo tem potencial para estimular novas pesquisas na área e também incentivar que docentes conheçam e comecem a utilizar o modelo de aula invertida em suas instituições.

Como limitações, aponta-se o fato de ser um estudo local e o fato de não ter sido possível entrevistar estudantes que tinham conceitos na faixa de regular como pretendido inicialmente. Esse fator pode ter tendenciada a realização de estudantes que tinham mais afinidade pelo modelo de aula invertida. Além disso, o único instrumento de coleta de dados utilizado foi a entrevista semiestruturada. Talvez o uso de observação não participante pudesse ter auxiliado em melhor compreensão dos fenômenos aqui relatados.

Espera-se que o estudo possa contribuir com novas pesquisas na área temática, bem como incentivar professores a utilizarem (ou pelo menos testarem) outras metodologias. Acredita-se que pesquisas na área de formação podem contribuir para um melhor engajamento dos alunos e, dessa forma, auxiliar nos processos de ensino e aprendizagem. Faz-se necessário investigar experiências de estudantes de enfermagem, em outros ambientes de sala de aula invertida, para uma compreensão mais profunda de como o aprendizado é afetado por esse modelo.

\section{REFERÊNCIAS}

1- Ministério da Educação (BR). Resolução CNE/CES no. 3, de 7/11/2001. Institui Diretrizes curriculares nacionais do curso de graduação em enfermagem. Diário Oficial da União 09 nov 2001; Seção 1.

2- Ciampone MHT, Kurcgant P. O ensino de administração em Enfermagem no Brasil: $O$ processo de construção de competências gerenciais. Rev Bras Enferm 2004;57(4):401-7. DOI: $10.1590 / S 0034-71672004000400003$.

3- Santos JLG, Souza BN, Simone C, Vieira FST, Sebold LF, Kempfer SS. Estratégias didáticas no processo de ensino-aprendizagem de gestão em enfermagem. Texto \& Contexto-Enferm. 2018; 27(2):e1980016. DOI: $10.1590 / 0104-$ 070720180001980016.

4- Menegaz JC, Dias GAR, Trindade RFS, Leal SN, Martins NKA. Flipped Classroom no ensino de gerenciamento em enfermagem: Relato de experiência. Esc Anna Nery 2018;22(3): e20170312. DOI: 10.1590/2177-9465-ean-20170312.

5- Green RD, Schlairet MC. Moving toward heutagogical learning: Illuminating undergraduate nursing students' experiences in a flipped classroom. Nurse Educ Today 2017;49:122-8. DOI: 10.1016/j.nedt.2016.11.016

6- Sajid MR, Laheji AF, Abothenain F, Salam Y, AlJayar D, Obeidat A. Can blended learning and the flipped classroom improve student learning and satisfaction in Saudi Arabia? Int J Med Educ. 2016; 7:281-5. DOI: 10.5116/ijme.57a7.83d4

7- Park SE, Howell TH. Implementation of a flipped classroom educational model in a predoctoral dental course. J Dent Educ. 2015 [citado em 15 jan 2019]; 79(5):563-70. Available in:

http://www.jdentaled.org/content/79/5/563.sho rt.

8- Lazzari DD, Pedro ENR, Sanches MO, Jung W. Estratégias de ensino do cuidado em enfermagem: Um olhar sobre as tendências pedagógicas. Rev Gaúcha Enferm. 2011;32(4):688-94. DOI: 10.1590/S1983-14472011000400008.

9- Torregrosa JF, Rodríguez MAJ, Estelles JT, Farinós FG, Bermejo MP, Ehrling NF. Distance learning ects and flipped classroom in the anatomy learning: Comparative study of the use of augmented reality, video and notes. BMC Med Educ. 2016;16:230. DOI: 10.1186/s12909-0160757-3.

10- Valente JA. Blended learning and changes in higher education: The inverted classroom proposal. Educ Rev. 2014;nesp:79-97. DOI: 10.1590/0104-4060.38645.

11- Gillispie V. Using the flipped classroom to bridge the gap to generation Y. Ochsner J. 2016 
[citado em 15 jan 2019]; 16:32-6. Available in: https://www.ncbi.nlm.nih.gov/pubmed/2704640 1

12- Medeiros AL, Santos SR, Cabral RWL. Sistematização da assistência de enfermagem na perspectiva dos enfermeiros: Uma abordagem metodológica na teoria fundamentada. Rev Gaúcha Enferm 2012;33:174-81. DOI: 10.1590/S1983-14472012000300023.

13- Novak GM. Just-in-time teaching. New Dir Teach Learn 2011;128:63-73. DOI: 10.1002/tl.469 14- Oliveira V, Veit EA, Araujo IS. Relato de experiência com os métodos Ensino sob Medida (Just-in-Time Teaching) e Instrução pelos Colegas (Peer Instruction) para o Ensino de Tópicos de Eletromagnetismo no nível médio.

Cad Bras Ensino Fís. 2015; 32: 180-206. DOI: 10.5007/2175-7941.2015v32n1p180

15- Bollela VR, Senger MH, Tourinho FSV, Amaral E. Aprendizagem baseada em equipes: Da teoria à prática. Medicina 2014;47(3):293-30. DOI: 10.11606/issn.2176-7262.v47i3p293-300

16- Michaelsen LK, Knight AB, Fink LD. Teambased learning: $A$ transformative use of small groups in college teaching. Sterling, VA: LLC; 2004. 17- Strauss A, Corbin J. Techniques and procedures for developing grounded theory. 3th ed. Thousand Oaks: Basics of Qualitative Research; 2008.

18- Schmitt CS, Domingues MJCS. Estilos de aprendizagem: Um estudo comparativo. Avaliação 2016;21(2):361-86. DOI: 10.1590/S1414-40772016000200004

19- Simpson V, Richards E. Flipping the classroom to teach population health: Increasing the relevance. Nurse Educ Pract. 2015;15(3):162-7. DOI: 10.1016/j.nepr.2014.12.001

20- Caligaris $M$, Rodríguez $G$, Laugero $L$. A first experience of flipped classroom in numerical analysis. Procedia Soc Behav Sci. 2016;217:838 45. DOI: 10.1016/j.sbspro.2016.02.158

21- Tan C, Yue WG, Fu Y. Effectiveness off lipped classrooms in nursing education: Systematic review andmeta-analysis. Chin Nurs Res. 2017; 4: 192-200. DOI 10.1016/j.cnre.2017.10.006

22- Sojayapan C, Khlaisang J. The effect of aflipped classroom with online group investigationon students' team learning ability. Kasetsart J Soc Sci. 2018; 30:1-6. DOI: 10.1016/i.kjss.2018.02.003

23- Chiavenato I. Comportamento organizacional: A teoria e a prática de inovar. Rio de Janeiro: Campos; 2005.

24- Hanson J. Surveying the experiences and perceptions of undergraduate nursing students of a flipped classroom approach to increase understanding of drug science and its application to clinical practice. Nurse Educ. 2016;16(1):79-85. DOI: 10.1016/j.nepr.2015.09.001

25- Mehta NB, Hull AL, Young JB, Stoller JK. Just imagine: New paradigms for medical education. Acad Med. 2013;88(10):1418-23. DOI: 10.1097/ACM.0b013e3182a36a07

Nota: Pesquisa originada de um Trabalho de Conclusão de Curso apresentado a Faculdade de Enfermagem da Universidade Federal do Pará para aquisição dos títulos de bacharel e licenciado em Enfermagem.

Recebido em: 22/09/19

Aprovado em: 22/05/20

Endereço de correspondência: Rua Augusto Corrêa, 01 Guamá, Belém - PA, 66075-110 (Faculdade de EnfermagemUFPA)

e-mail: ricky.trindade@ics.ufpa.br 